\title{
Cause-specific mortality after a breast cancer diagnosis: a cohort study of 10,195 women in Girona and Tarragona
}

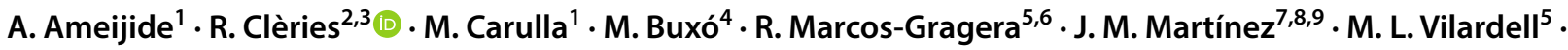 \\ M. Vilardell ${ }^{10} \cdot$ J. A. Espinàs ${ }^{2} \cdot$ J. M. Borràs ${ }^{2,3} \cdot$ Á. Izquierdo ${ }^{5,11} \cdot$ J. Galceran $^{1}$
}

Received: 4 December 2018 / Accepted: 10 December 2018 / Published online: 3 January 2019

(C) The Author(s) 2018

\begin{abstract}
Introduction Evidence suggests an excess of long-term mortality due to cardiovascular diseases, second tumours and other causes in patients diagnosed with invasive breast cancer (BC). Our aim was to assess this risk of death in a cohort of patients diagnosed with BC in Girona and Tarragona, northeastern Spain.

Materials and methods Using data from the cancer registries in these areas, a population-based cohort study was carried out including all the women diagnosed with BC during 1985-2004 and followed up until December 31 st $2014(N=10,195)$. The standardised mortality ratios (SMRs) were calculated for causes other than BC in the cohort at 10 years (periods 19851994/1995-2004) and 20 years (period 1985-1994). The impact of competing causes of death in the long-term survival was evaluated through competing risk analysis.

Results The SMRs at 10 and 20 years for all-cause mortality, except BC, were 1.21 and 1.22 . The main causes of mortality showing statistically significant SMR at 10 years were other tumours (colon, lung, corpus uteri, ovary, and haematological), diabetes mellitus, diseases of the nervous system, cardiovascular diseases (after BC, the second competing cause of death among patients diagnosed $>69$ years) and diseases of the kidney. Globally, the 10-year SMR was higher in the first period. After 20 years of follow-up (1985-1994 cohort), there were 48.5 excess deaths per 10,000 patient-years for causes other than BC.

Conclusions Women who did not die from BC at 10 or 20 years after the BC diagnosis had $20 \%$ higher risk of dying from other causes than women without BC. This excess risk must be clinically considered during 20 years after the BC diagnosis.
\end{abstract}

Keywords Breast cancer $\cdot$ Cause-specific mortality $\cdot$ Excess mortality $\cdot$ Side effects $\cdot$ Second tumour

Electronic supplementary material The online version of this article (https://doi.org/10.1007/s12094-018-02015-5) contains supplementary material, which is available to authorized users.

\section{R. Clèries}

r.cleries@iconcologia.net

1 Registre de Càncer de Tarragona, Fundació per a la investigació i la prevenció del Càncer (FUNCA), IISPV, Reus, Spain

2 Pla Director d'Oncologia, IDIBELL, Hospitalet de Llobregat, Spain

3 Department de Ciències Clíniques, Universitat de Barcelona, Barcelona, Spain

4 Institut d'Investigació Biomèdica de Girona, IDIBGI, Parc Hospitalari Martí i Julià, Salt, Spain

5 Registre de Càncer de Girona-Unitat d'Epidemiologia, Pla Director d'Oncologia, Institut Català d'Oncologia, Grup d'Epidemiologia Descriptiva, Genètica i Prevenció del Càncer de Girona-IDIBGI, Girona, Spain
6 Consortium for Biomedical Research in Epidemiology and Public Health (CIBERESP), Carlos III Institute of Health, Av/Monforte de Lemos, 5, 28029 Madrid, Spain

7 Departamento de Investigación y Análisis de Prestaciones, MC MUTUAL, Barcelona, Spain

8 Departament d'Estadística i Investigació Operativa, Universitat Politècnica de Catalunya, Barcelona, Spain

9 Public Health Research Group, University of Alicante, Alicante, Spain

10 Secció d'Estadística del Departament de Genètica, Microbiología i Estadística de la Facultat de Biología, Universitat de Barcelona, Barcelona, Spain

11 Departament d'Oncologia Médica, Institut Català d'Oncologia, Hospital Universitari Doctor Josep Trueta, Girona, Spain 


$\begin{array}{ll}\text { Abbreviations } \\ \text { BC } & \text { Breast cancer } \\ \text { RT } & \text { Radiotherapy } \\ \text { CVD } & \text { Cardiovascular disease } \\ \text { EM } & \text { Excess of mortality } \\ \text { ICD } & \text { International classification of diseases } \\ \text { SMR } & \text { Standardised mortality ratio } \\ \text { O } & \text { Observed number of deaths } \\ \text { E } & \text { Expected number of deaths } \\ \text { ED } & \text { Excess in the number of deaths } \\ \text { 95\% CI } & 95 \% \text { confidence interval } \\ \text { OC } & \text { Other causes of mortality, excludes BC, cancer } \\ & \text { and CVD } \\ \text { SupMat } & \text { Supplementary material } \\ \text { Gy } & \text { Dose in radiation therapy measured in grays }\end{array}$

\section{Introduction}

Breast cancer (BC) is the most frequent tumour and the first cause of cancer death in Spanish and European women in recent decades $[1,2]$. It is estimated that 27,700 new $\mathrm{BC}$ cases were diagnosed in Spain during 2015 [2]. In Spain and Europe, mortality from BC has significantly decreased in recent decades and 5-year survival has increased [1, 3, 4] as a result of early diagnosis and of therapeutic improvements in chemotherapy, hormonal treatment and radiotherapy (RT) [4-6]. At European level, recent estimates indicate that $12 \%$ of the women who survived BC beyond 5 years of diagnosis died from this cause before 10 years of diagnosis [7]. In the long-term, evidence suggests in them an increased risk of cardiovascular disease (CVD) and second primary tumours as a consequence of the treatments (RT and some types of chemotherapy) [8-11].

The long-term survival of the cohort used in the present study was previously analysed estimating the probability to die from BC [12], and showing an excess mortality (EM) at 15-20 years mainly attributed to BC. Given the average of the age at the diagnosis of $\mathrm{BC}, 60$ years [2, 12], and the increase in women's life expectancy [12], the objective of this study is to assess the causes of mortality associated with the diagnosis and treatment of BC in a cohort of patients diagnosed in the northeastern Spain, at 10 and 20 years after the $\mathrm{BC}$ diagnosis.

\section{Materials and methods}

A population-based cohort study was performed using data from the population-based cancer registries of Tarragona and Girona. All women aged 15-84 years diagnosed with invasive primary $\mathrm{BC}$ in these regions during the years (periods) 1985-1994 $(N=4211)$ and 1995-2004 $(N=5984)$ were included. Details of this cohort are described elsewhere [12].

The vital status of these patients was followed until December 31st 2014 through passive follow-up ('record linkage' between the databases of cancer registries with those of the Mortality Registry of Catalonia and the National Index of Deaths of the Spanish Ministry of Health) and active follow-up. In this process, the causes of death were retrieved and posteriorly assessed using the International Classification of Diseases (ICD) in its tenth edition. The information of the patients with an ill-defined malignancy death code (C76-C80, C97) was reviewed within the record files of the cancer registries and in the patient's medical records to determine the exact cause of death.

\section{Statistical analysis}

The EM was evaluated for mortality causes other than BC at 20 years for those patients diagnosed during the time period 1985-1994, and at 10 years for those diagnosed during 1985-1994, 1995-2004 and 1985-2004.

The standardised mortality ratio (SMR) was calculated as the ratio between the observed number of deaths $(\mathrm{O})$ from a certain mortality cause at 10 and 20 years after the diagnosis of BC and the expected (E) deaths at that time if the patients in the cohort experienced the same mortality rates from that cause as the reference population [13]. Then E was calculated by applying the age and year-specific personyears at risk in the cohort by the corresponding cause-specific mortality rates of Catalonia, the reference population which comprises the areas of Girona and Tarragona. The person-years observed were defined as the period between the $\mathrm{BC}$ diagnosis and the first dates reached between (a) the date of death and (b) the date of the last-known vital status (December 31st 2014) after the BC was diagnosed. The 95\% confidence intervals of the SMR $(95 \% \mathrm{CI})$ were calculated assuming that $\mathrm{O}$ follows a Poisson distribution [13]. Finally, we also calculated the excess of deaths (ED), the difference between the observed and expected cause-specific mortality rates [13] per 10,000 patient-years, to assess the contribution of each cause of death to the overall mortality.

The SMRs were evaluated for all causes of death as a whole, except BC, and for a grouped causes of death according to ICD-10: (1) tumours (C00-D49), (2) diseases of the blood (D50-D89), (3) endocrine organs (E00-E89), (4) nervous system (G00-G99), (5) circulatory system (CVD:I00-I99), (6) respiratory system (J00-J99), (7) digestive system (K00-K95), (8) musculoskeletal system (M00-M99), (9) genitourinary system (N00-N99), (10) malformations and other unclassified findings (Q00-Q99). The differences in the 10-year SMR between 1985-1994 
and 1995-2004 were assessed through a log-linear Poisson model using a time-trend effect [13].

We also assessed the 10-year survival under competing causes of death setting [12], by comparing the cumulative mortality - see supplementary material (SupMat) for statistical methods and tables of results related to this specific analysis-due to four causes: BC, cancer (excluding BC), $\mathrm{CVD}$, and the group of the remaining (other) causes of death (OC) stratified by age groups and cancer stage at diagnosis, this latter was available in period 1995-2004 [12]. All analyses were performed using the software R (www.cran-r.org).

\section{Results}

Among 10,195 women diagnosed with BC between 1985 and 2004, a total of 4127 (40.5\%) had died 10 years after the diagnosis: 3179 due to cancer and 948 due to other causes. Among those who had died of cancer, 2857 were due to BC (69\% of all deaths, $73 \%$ among those diagnosed in the 1985-1994 period and 65\% among those diagnosed between 1995 and 2004). Among the 4211 patients diagnosed with BC between 1985 and 1994, 2797 (66.4\%) had died 20 years after the BC was diagnosed: 2017 of them due to cancer (1781 due to BC, $64 \%$ of the total deaths) and 780 for causes other than cancer. Among the 10,195 patients diagnosed during 1985-2004, the all-cause SMR at 10 years was 3.18 (CI 95\% 3.08-3.17) and 10.48 (CI 95\% 10.12-10.45) for dying from any tumour (including BC). According to the death certificates, we finally found $N=34$ poorly defined localization or uncertain behaviour tumours (see SupMat for details).

Table 1 shows the 10-year SMR among the 7338 patients diagnosed during 1985-2004 who did not die from BC. Since their all-cause SMR was 1.21, there were also detected significant SMRs in (a) tumours ( $\mathrm{SMR}=1.48)$, and among these in colon $(\mathrm{SMR}=1.44)$, lung $(\mathrm{SMR}=2.26)$, bone and cartilage ( $\mathrm{SMR}=7.64)$, corpus uteri $(\mathrm{SMR}=2.85)$, ovary $(\mathrm{SMR}=2.20)$, haematological no-leukaemia $(\mathrm{SMR}=1.72)$ and leukaemias ( $\mathrm{SMR}=2.05)$; and (b) non-tumours, such as in diabetes mellitus (SMR $=1.43$ ), diseases of the nervous system $(\mathrm{SMR}=1.30)$, diseases of the circulatory system $(\mathrm{SMR}=1.12$; "Other diseases of the heart" $\mathrm{SMR}=1.58)$, pathological fracture (SMR $=2.17$ ), diseases of the genitourinary system $(\mathrm{SMR}=1.55)$, kidney-ureter $(\mathrm{SMR}=1.62)$ and other congenital malformations ( $\mathrm{SMR}=8.72$ ). Heart failure and cerebrovascular diseases showed non-statistically significant SMR. The SMR in the first 10 -year period was higher than in the second one $\left(\mathrm{SMR}_{1985-1994}=1.29\right.$; $\mathrm{SMR}_{1995-2004}=1.16$ ) in particular in (a) tumours $\left(\mathrm{SMR}_{1985-1994}=1.69 ; \mathrm{SMR}_{1995-2004}=1.34\right)$, and among these in lung $\left(\mathrm{SMR}_{1985-1994}=3.90 ; \mathrm{SMR}_{1995-2004}=1.54\right)$, bone and cartilages $\left(\mathrm{SMR}_{1985-1994}=10.25 ; \mathrm{SMR}_{1995-2004}=5.53\right)$, ovary
$\left(\mathrm{SMR}_{1985-1994}=3.34 ; \mathrm{SMR}_{1995-2004}=1.50\right)$ and haematological no leukaemia $\left(\mathrm{SMR}_{1985-1994}=2.83 ; \mathrm{SMR}_{1995-2004}=1.05\right)$; and in (b) diseases of the nervous system except for meningitis and Alzheimer's disease $\left(\mathrm{SMR}_{1985-1994}=2.37\right.$; $\mathrm{SMR}_{1995-2004}=1.10$ ), and diseases of the kidney and ureter $\left(\mathrm{SMR}_{1985-1994}=2.34 ; \mathrm{SMR}_{1995-2004}=1.21\right)$. Circulatory system diseases maintained a similar risk in both periods, except for the group "Other heart diseases" $\left(\mathrm{SMR}_{1985-1994}=1.94\right.$; $\mathrm{SMR}_{1995-2004}=1.37$ ).

Table 2 shows the 20-year SMR among the 2430 patients diagnosed during 1985-1994 and who did not die from BC. Their all-cause SMR was 1.22, and the causes of death presenting also a significant $\mathrm{SMR}$ in tumours $(\mathrm{SMR}=1.57)$ were lung ( $\mathrm{SMR}=2.57)$, bone and cartilage $(\mathrm{SMR}=6.42)$, corpus uteri (SMR $=3.67)$, ovary $(\mathrm{SMR}=2.51)$, and haematological no-leukaemia (SMR $=2.14)$. Among non-tumours, these were diabetes mellitus (SMR $=1.65)$, other diseases of the nervous system $(\mathrm{SMR}=1.93)$, diseases of the circulatory system ( $\mathrm{SMR}=1.12$ ), especially the other diseases of the heart $(\mathrm{SMR}=1.50)$, and diseases of the kidney and ureter $(\mathrm{SMR}=1.79)$. Heart failure $(\mathrm{SMR}=1.28)$ was at the limit of statistical significance. Differences in 10-year and 20-year SMRs were not significant (note that for all-cause mortality during 1985-1994 were similar, $\mathrm{SMR}_{10 \text {-year }}=1.29$, whereas $\mathrm{SMR}_{20 \text {-year }}=1.22$ ).

The 20-year ED for causes other than BC was 48.5 per 10,000 patient-years, where 7 causes with significant SMR contributed to $55 \%$ (26.83 deaths out of 48.5 ) to that ED: other heart diseases (5.04), uterine corpus tumours (4.41), diabetes mellitus (4.24), lung tumour (4.02), malignant hematologic tumours except leukaemia (3.09), diseases of the kidney and ureter (3.02), and tumour of the ovary (3.01).

Finally, comparing competing risks of death 10 years after the BC diagnosis by cancer stage (Figs. 1, 2; see also Tables S1-S4 in SupMat) we found that: (a) in stage I, patients diagnosed before 69 years were more likely to die from any cancer, whereas those diagnosed later were more likely to die from CVD or OC than from any cancer; (b) the probability to die from CVD and OC surpasses that of cancer excluding BC in stages II and III among patients diagnosed $>59$ years and (c) patients diagnosed in stage IV had the largest probabilities to die from any cancer.

\section{Discussion}

The knowledge of the causes of death other than $\mathrm{BC}$ in a cohort of patients diagnosed with BC sheds light in interpreting long-term mortality/survival in relation to other diseases and, especially, second cancers, where we must also take into account the factors other than treatment itself [14]. Our study period covers two diagnostic periods: (a) 1985-1994, prior to a time period of improvements in RT 
Table 1 Risk of death at 10 years after the diagnosis of breast cancer in the regions of Girona and Tarragona during the period 1985-1994: causes of death other than breast cancer

\begin{tabular}{|c|c|c|c|c|c|c|c|c|}
\hline \multirow[t]{2}{*}{ Groups of causes of death (ICD-10) } & \multicolumn{3}{|c|}{ 1985-2004 } & \multicolumn{2}{|c|}{ 1985-1994 } & \multicolumn{2}{|c|}{ 1995-2004 } & \multirow{2}{*}{$\begin{array}{l}\text { Trend-SMR } \\
\text { 1995-2004/1985-1994 } \\
p \text { value test }\end{array}$} \\
\hline & (O) & SMR & $95 \% \mathrm{CI}$ & (O) & SMR & $(\mathrm{O})$ & SMR & \\
\hline All causes (except breast cancer) & 1267 & 1.21 & $1.14-1.28 *$ & 538 & $1.29 *$ & 729 & $1.15^{*}$ & $* *$ \\
\hline Infectious and parasitic diseases & 15 & 1.04 & $0.58-1.72$ & 2 & 0.51 & 13 & 1.22 & \\
\hline Tumours (except breast) & 319 & 1.48 & $1.32-1.65^{*}$ & 140 & $1.69^{*}$ & 179 & $1.34 *$ & $* *$ \\
\hline Malignant tumour of lip, oral cavity and pharynx & 5 & 1.87 & $0.59-4.39$ & 1 & 1.04 & 4 & 2.33 & \\
\hline Malignant tumour of oesophagus & 1 & 0.57 & $0.00-3.29$ & 1 & 1.49 & 0 & 0.00 & \\
\hline Malignant tumour of stomach & 19 & 1.24 & $0.74-1.94$ & 5 & 0.73 & 14 & 1.65 & \\
\hline Malignant tumour of colon & 43 & 1.44 & $1.04-1.94 *$ & 16 & 1.42 & 27 & 1.45 & \\
\hline Malignant tumour of rectum, recto-sigmoid junction and anus & 9 & 1.08 & $0.49-2.05$ & 4 & 1.15 & 5 & 1.02 & \\
\hline Malignant tumour of liver and biliary tract & 18 & 1.47 & $0.87-2.32$ & 8 & 1.59 & 10 & 1.38 & \\
\hline Malignant tumour of pancreas & 21 & 1.40 & $0.87-2.15$ & 7 & 1.40 & 14 & 1.41 & \\
\hline Other malignant digestive tumours & 8 & 0.84 & $0.36-1.66$ & 6 & 1.43 & 2 & 0.38 & \\
\hline Malignant tumour of larynx & 1 & 2.30 & $0.00-13.20$ & 0 & 0.00 & 1 & 3.45 & \\
\hline Malignant tumour of trachea, bronchus and lung & 36 & 2.26 & $1.58-3.13 *$ & 19 & $3.90^{*}$ & 17 & 1.54 & $* *$ \\
\hline Other malignant respiratory and intrathoracic tumours & 2 & 1.64 & $0.15-6.03$ & 2 & 4.16 & 0 & 0.00 & \\
\hline Malignant tumour of bone and articular cartilages & 5 & 7.64 & $2.41-17.98^{*}$ & 3 & $10.25^{*}$ & 2 & 5.53 & $* *$ \\
\hline Malignant melanoma of skin & 2 & 0.93 & $0.09-3.40$ & 1 & 1.36 & 1 & 0.70 & \\
\hline Other malignant tumours of skin and soft tissues & 5 & 2.23 & $0.70-5.24$ & 1 & 1.35 & 4 & 2.67 & \\
\hline Malignant tumour of cervix uteri & 2 & 0.57 & $0.05-2.09$ & 1 & 0.67 & 1 & 0.49 & \\
\hline Malignant tumour of other parts of uterus & 26 & 2.85 & $1.86-4.18^{*}$ & 9 & $2.33^{*}$ & 17 & $3.23 *$ & \\
\hline Malignant tumour of ovary & 26 & 2.20 & $1.43-3.23^{*}$ & 15 & $3.34 *$ & 11 & 1.50 & $* *$ \\
\hline Malignant tumour of other genital female organs & 0 & 0.00 & $0.00-1.19$ & 0 & 0.00 & 0 & 0.00 & \\
\hline Malignant tumour of kidney, except renal pelvis & 2 & 0.54 & $0.05-2.00$ & 1 & 0.74 & 1 & 0.43 & \\
\hline Malignant tumour of urinary bladder & 3 & 0.56 & $0.11-1.66$ & 2 & 0.94 & 1 & 0.31 & \\
\hline Other malignant tumours of urinary tract & 0 & 0.00 & $0.00-5.73$ & 0 & 0.00 & 0 & 0.00 & \\
\hline Malignant tumour of encephalon & 6 & 0.88 & $0.32-1.93$ & 2 & 0.86 & 4 & 0.89 & \\
\hline Other neurological and endocrine malignant tumours & 2 & 0.99 & $0.09-3.64$ & 0 & 0.00 & 2 & 1.53 & \\
\hline $\begin{array}{l}\text { Malignant tumours of ill-defined. secondary and no specified } \\
\text { sites }\end{array}$ & 22 & 1.18 & $0.74-1.79$ & 7 & 0.91 & 15 & 1.38 & \\
\hline Haematological malignant tumours, except leukaemia & 26 & 1.72 & $1.12-2.52 *$ & 16 & $2.83 *$ & 10 & 1.05 & $* *$ \\
\hline Leukaemia & 19 & 2.05 & $1.23-3.20^{*}$ & 7 & 2.05 & 12 & $2.04 *$ & \\
\hline In situ tumours & 0 & 0.00 & $0.00-199.89$ & 0 & 0.00 & 0 & 0.00 & \\
\hline Benign tumours & 1 & 0.68 & $0.00-3.87$ & 0 & 0.00 & 1 & 1.03 & \\
\hline Myelodysplastic syndrome & 4 & 2.21 & $0.58-5.72$ & 1 & 2.39 & 3 & 2.16 & \\
\hline Other tumours of uncertain or unknown behaviour & 5 & 0.80 & $0.25-1.88$ & 4 & 1.61 & 1 & 0.27 & \\
\hline Diseases of the blood and the haematopoietic organs & 4 & 0.87 & $0.23-2.24$ & 3 & 1.75 & 1 & 0.34 & \\
\hline Endocrine, nutritional and metabolic diseases & 45 & 1.18 & $0.86-1.58$ & 17 & 1.19 & 28 & 1.17 & \\
\hline Diabetes mellitus & 45 & 1.43 & $1.04-1.92 *$ & 17 & 1.39 & 28 & 1.45 & \\
\hline Other endocrine, nutritional and metabolic diseases & 0 & 0.00 & $0.00-0.59 *$ & 0 & 0.00 & 0 & $0^{*}$ & \\
\hline Mental and behavioural disorders & 48 & 0.85 & $0.63-1.13$ & 18 & 0.96 & 30 & 0.79 & \\
\hline Diseases of the nervous system and of the organs of the senses & 65 & 1.30 & $1.00-1.66^{*}$ & 23 & $1.99 *$ & 42 & 1.07 & \\
\hline Meningitis & 1 & 2.36 & $0.00-13.54$ & 1 & 6.80 & 0 & 0.00 & \\
\hline Alzheimer's disease & 37 & 1.17 & $0.83-1.62$ & 9 & 1.52 & 28 & 1.07 & \\
\hline Other diseases of the nervous system and sense organs & 27 & 1.49 & $0.98-2.17$ & 13 & $2.37 *$ & 14 & 1.10 & $* *$ \\
\hline Circulatory system diseases & 393 & 1.12 & $1.01-1.24 *$ & 167 & 1.11 & 226 & 1.13 & \\
\hline Chronic rheumatic heart diseases & 6 & 0.88 & $0.32-1.93$ & 3 & 1.06 & 3 & 0.76 & \\
\hline Hypertensive diseases & 19 & 0.80 & $0.48-1.26$ & 3 & 0.41 & 16 & 0.97 & \\
\hline Acute myocardial infarction & 39 & 0.83 & $0.59-1.13$ & 15 & 0.71 & 24 & 0.94 & \\
\hline
\end{tabular}


Table 1 (continued)

\begin{tabular}{|c|c|c|c|c|c|c|c|c|}
\hline \multirow[t]{2}{*}{ Groups of causes of death (ICD-10) } & \multicolumn{3}{|c|}{ 1985-2004 } & \multicolumn{2}{|c|}{ 1985-1994 } & \multicolumn{2}{|c|}{ 1995-2004 } & \multirow{2}{*}{$\begin{array}{l}\text { Trend-SMR } \\
\text { 1995-2004/1985-1994 } \\
p \text { value test }\end{array}$} \\
\hline & (O) & SMR & $95 \% \mathrm{CI}$ & $(\mathrm{O})$ & SMR & $(\mathrm{O})$ & SMR & \\
\hline Other ischaemic diseases of the heart & 38 & 1.05 & $0.74-1.44$ & 12 & 0.84 & 26 & 1.17 & \\
\hline Heart failure & 73 & 1.20 & $0.94-1.51$ & 31 & 1.22 & 42 & 1.19 & \\
\hline Other heart diseases & 75 & 1.58 & $1.24-1.98^{*}$ & 33 & $1.94 *$ & 42 & 1.37 & $* *$ \\
\hline Cerebrovascular diseases & 120 & 1.15 & $0.95-1.37$ & 56 & 1.16 & 64 & 1.15 & \\
\hline Atherosclerosis & 12 & 0.84 & $0.43-1.47$ & 8 & 0.84 & 4 & 0.90 & \\
\hline Other diseases of blood vessels & 11 & 1.16 & $0.58-2.08$ & 6 & 1.59 & 5 & 0.87 & \\
\hline Diseases of the respiratory system & 75 & 0.97 & $0.76-1.21$ & 33 & 1.15 & 42 & 0.85 & \\
\hline Diseases of the digestive system & 63 & 1.28 & $0.98-1.64$ & 22 & 1.14 & 41 & 1.37 & \\
\hline Ulcer of stomach, duodenum and jejunum & 2 & 1.19 & $0.11-4.38$ & 1 & 1.06 & 1 & 1.39 & \\
\hline Non-infectious enteritis and colitis & 3 & 3.55 & $0.67-10.50$ & 1 & 3.56 & 2 & 3.51 & \\
\hline Bowel vascular disease & 3 & 0.39 & $0.07-1.17$ & 1 & 0.39 & 2 & 0.39 & \\
\hline Cirrhosis and other chronic diseases of the liver & 21 & 1.35 & $0.84-2.07$ & 8 & 1.16 & 13 & 1.52 & \\
\hline Other diseases of the digestive system & 34 & 1.44 & $1.00-2.02$ & 11 & 1.28 & 23 & 1.53 & \\
\hline Diseases of the skin and subcutaneous tissue & 2 & 0.89 & $0.08-3.27$ & 1 & 1.31 & 1 & 0.67 & \\
\hline Diseases of the musculoskeletal system and connective tissue & 19 & 1.63 & $0.98-2.55$ & 8 & 1.83 & 11 & 1.50 & \\
\hline Rheumatoid arthritis and osteoarthrosis & 3 & 1.60 & $0.30-4.73$ & 2 & 2.78 & 1 & 0.86 & \\
\hline Osteoporosis and pathological fracture & 14 & 2.17 & $1.18-3.64 *$ & 6 & 2.39 & 8 & 2.02 & \\
\hline $\begin{array}{l}\text { Other diseases of the musculoskeletal system and connective } \\
\text { tissue }\end{array}$ & 2 & 0.60 & $0.06-2.21$ & 0 & 0.00 & 2 & 0.91 & \\
\hline Diseases of the genitourinary system & 37 & 1.55 & $1.09-2.13^{*}$ & 15 & $1.85^{*}$ & 22 & 1.38 & \\
\hline Diseases of the kidney and the ureter & 29 & 1.62 & $1.08-2.33^{*}$ & 15 & $2.34 *$ & 14 & 1.21 & $* *$ \\
\hline $\begin{array}{l}\text { Diseases of the female genital organs and disorders of the } \\
\text { breast }\end{array}$ & 0 & 0.00 & $0.00-16.03$ & 0 & 0.00 & 0 & 0.00 & \\
\hline Other diseases of the genitourinary system & 8 & 1.38 & $0.59-2.73$ & 0 & 0.00 & 8 & 1.88 & \\
\hline $\begin{array}{l}\text { Congenital malformations, deformities and chromosomal } \\
\text { abnormalities }\end{array}$ & 4 & 5.01 & $1.30-12.94 *$ & 1 & 3.60 & 3 & $5.72 *$ & \\
\hline Congenital malformations of the nervous system & 0 & 0.00 & $0.00-138.22$ & 0 & 0.00 & 0 & 0.00 & \\
\hline Congenital malformations of the circulatory system & 0 & 0.00 & $0.00-12.57$ & 0 & 0.00 & 0 & 0.00 & \\
\hline $\begin{array}{l}\text { Other congenital malformations, deformities and chromo- } \\
\text { somal abnormalities }\end{array}$ & 4 & 8.72 & $2.27-22.54 *$ & 1 & 7.59 & 3 & $9.06 *$ & \\
\hline $\begin{array}{l}\text { Symptoms, signs and abnormal findings not elsewhere classi- } \\
\text { fied }\end{array}$ & 25 & 1.22 & $0.79-1.80$ & 8 & 1.06 & 17 & 1.30 & \\
\hline $\begin{array}{l}\text { Cardiac arrest, death without assistance and other unknown } \\
\text { cause of mortality }\end{array}$ & 13 & 1.35 & $0.71-2.31$ & 2 & 0.56 & 11 & 1.80 & \\
\hline Senility & 4 & 0.72 & $0.19-1.86$ & 2 & 0.85 & 2 & 0.62 & \\
\hline Rest of symptoms, signs and clinical abnormal findings & 8 & 1.49 & $0.64-2.96$ & 4 & 2.48 & 4 & 1.06 & \\
\hline External causes of mortality & 32 & 1.21 & $0.83-1.71$ & 15 & 1.60 & 17 & 1.00 & \\
\hline
\end{tabular}

$O$ observed deaths; SMR standardised mortality ratio; $95 \%$ CI 95\% confidence interval of the SMR

*Statistically significant at $\alpha=0.05$

** Test for comparing whether SMR in the first 10-year period, 1985-1994, was significantly different to that of the second period, 1995-2004, at $\alpha=0.05$

techniques and planning [15], and (b) 1995-2004, with some years before these changes took place and some years after these were established [12]. In relation to the medical treatments, tamoxifen was administered since 1985 to BC patients diagnosed in Girona and Tarragona [12].

In a previous study, we showed that the largest EM was due to BC [12]. In the present study, the SMRs from certain causes other than $\mathrm{BC}$ were significant and 10 -year risk was higher in women diagnosed in the first decade than in the second $\left(\mathrm{SMR}_{1985-1994}=1.29\right.$; $\left.\mathrm{SMR}_{1995-2004}=1.15\right)$. The SMR of cancer excepting BC was statistically significant and slightly decreased from the first to the second decade of the study. 
Table 2 Risk of death at 20 years after the diagnosis of breast cancer in the regions of Girona and Tarragona during the period 1985-1994: causes of death other than breast cancer

\begin{tabular}{|c|c|c|c|}
\hline \multirow[t]{2}{*}{ Groups of causes of death (ICD-10) } & \multicolumn{3}{|c|}{ 1985-1994 } \\
\hline & $(\mathrm{O})$ & SMR & $95 \% \mathrm{CI}$ \\
\hline All causes (except breast cancer) & 1013 & 1.22 & $1.15-1.30 *$ \\
\hline Infectious and parasitic diseases & 6 & 0.58 & $0.21-1.28$ \\
\hline Tumours (except breast) & 233 & 1.57 & $1.37-1.78 *$ \\
\hline Malignant tumour of lip, oral cavity and pharynx & 3 & 1.67 & $0.31-4.93$ \\
\hline Malignant tumour of oesophagus & 2 & 1.69 & $0.16-6.23$ \\
\hline Malignant tumour of stomach & 11 & 1.00 & $0.49-1.79$ \\
\hline Malignant tumour of colon & 28 & 1.34 & $0.89-1.94$ \\
\hline Malignant tumour of rectum, recto-sigmoid junction and anus & 9 & 1.52 & $0.69-2.91$ \\
\hline Malignant tumour of liver and biliary tract & 11 & 1.29 & $0.64-2.31$ \\
\hline Malignant tumour of pancreas & 13 & 1.30 & $0.69-2.24$ \\
\hline Other malignant digestive tumours & 10 & 1.44 & $0.68-2.66$ \\
\hline Malignant tumour of larynx & 0 & 0.00 & $0.00-14.69$ \\
\hline Malignant tumour of trachea, bronchus and lung & 25 & 2.57 & $1.66-3.80^{*}$ \\
\hline Other malignant respiratory and intrathoracic tumours & 2 & 2.42 & $0.23-8.91$ \\
\hline Malignant tumour of bone and articular cartilages & 3 & 6.42 & $1.21-19.01 *$ \\
\hline Malignant melanoma of skin & 2 & 1.45 & $0.14-5.32$ \\
\hline Other malignant tumours of skin and soft tissues & 2 & 1.26 & $0.12-4.65$ \\
\hline Malignant tumour of cervix uteri & 2 & 0.89 & $0.08-3.28$ \\
\hline Malignant tumour of other parts of uterus & 23 & 3.67 & $2.33-5.52 *$ \\
\hline Malignant tumour of ovary & 19 & 2.51 & $1.51-3.93^{*}$ \\
\hline Malignant tumour of other genital female organs & 2 & 0.82 & $0.08-3.03$ \\
\hline Malignant tumour of kidney, except renal pelvis & 4 & 1.60 & $0.42-4.13$ \\
\hline Malignant tumour of urinary bladder & 4 & 0.99 & $0.26-2.56$ \\
\hline Other malignant tumours of urinary tract & 0 & 0.00 & $0.00-8.89$ \\
\hline Malignant tumour of encephalon & 5 & 1.20 & $0.38-2.82$ \\
\hline Other neurological and endocrine malignant tumours & 0 & 0.00 & $0.00-2.93$ \\
\hline Malignant tumours of ill-defined, secondary and no specified sites & 14 & 1.05 & $0.57-1.76$ \\
\hline Haematological malignant tumours, except leukaemia & 22 & 2.14 & $1.34-3.25^{*}$ \\
\hline Leukaemia & 9 & 1.41 & $0.64-2.68$ \\
\hline In situ tumours & 0 & 0.00 & $0.00-299.76$ \\
\hline Benign tumours & 0 & 0.00 & $0.00-3.85$ \\
\hline Myelodysplastic syndrome & 1 & 0.73 & $0.00-4.20$ \\
\hline Other tumours of uncertain or unknown behaviour & 6 & 1.30 & $0.47-2.84$ \\
\hline Diseases of the blood and the haematopoietic organs & 5 & 1.32 & $0.42-3.11$ \\
\hline Endocrine, nutritional and metabolic diseases & 45 & 1.50 & $1.09-2.01 *$ \\
\hline Diabetes mellitus & 41 & 1.65 & $1.18-2.23 *$ \\
\hline Other endocrine, nutritional and metabolic diseases & 4 & 0.78 & $0.20-2.03$ \\
\hline Mental and behavioural disorders & 36 & 0.72 & $0.50-1.00^{*}$ \\
\hline Diseases of the nervous system and of the organs of the senses & 58 & 1.51 & $1.14-1.95^{*}$ \\
\hline Meningitis & 2 & 6.99 & $0.66-25.72$ \\
\hline Alzheimer's disease & 31 & 1.23 & $0.83-1.74$ \\
\hline Other diseases of the nervous system and of the sense organs & 25 & 1.93 & $1.25-2.85^{*}$ \\
\hline Circulatory system diseases & 327 & 1.12 & $1.00-1.25^{*}$ \\
\hline Chronic rheumatic heart diseases & 6 & 1.22 & $0.44-2.68$ \\
\hline Hypertensive diseases & 9 & 0.45 & $0.20-0.85^{*}$ \\
\hline Acute myocardial infarction & 38 & 1.02 & $0.72-1.40$ \\
\hline Other ischaemic diseases of the heart & 26 & 0.86 & $0.56-1.27$ \\
\hline
\end{tabular}


Table 2 (continued)

\begin{tabular}{|c|c|c|c|}
\hline \multirow[t]{2}{*}{ Groups of causes of death (ICD-10) } & \multicolumn{3}{|c|}{ 1985-1994 } \\
\hline & (O) & SMR & $95 \%$ CI \\
\hline Heart failure & 69 & 1.28 & $1.00-1.62$ \\
\hline Other heart diseases & 57 & 1.50 & $1.14-1.95^{*}$ \\
\hline Cerebrovascular diseases & 104 & 1.19 & $0.97-1.45$ \\
\hline Atherosclerosis & 10 & 0.75 & $0.36-1.38$ \\
\hline Other diseases of blood vessels & 8 & 1.03 & $0.44-2.04$ \\
\hline Diseases of the respiratory system & 73 & 1.13 & $0.89-1.42$ \\
\hline Diseases of the digestive system & 37 & 0.98 & $0.69-1.35$ \\
\hline Ulcer of stomach, duodenum and jejunum & 2 & 1.42 & $0.13-5.22$ \\
\hline Non-infectious enteritis and colitis & 3 & 4.41 & $0.83-13.05$ \\
\hline Bowel vascular disease & 2 & 0.33 & $0.03-1.21$ \\
\hline Cirrhosis and other chronic diseases of the liver & 11 & 1.04 & $0.52-1.87$ \\
\hline Other diseases of the digestive system & 19 & 1.00 & $0.60-1.57$ \\
\hline Diseases of the skin and subcutaneous tissue & 2 & 1.05 & $0.10-3.87$ \\
\hline Diseases of the musculoskeletal system and connective tissue & 15 & 1.52 & $0.85-2.52$ \\
\hline Rheumatoid arthritis and osteoarthrosis & 3 & 2.10 & $0.40-6.22$ \\
\hline Osteoporosis and pathological fracture & 11 & 1.84 & $0.92-3.31$ \\
\hline Other diseases of the musculoskeletal system and connective tissue & 1 & 0.41 & $0.00-2.33$ \\
\hline Diseases of the genitourinary system & 31 & 1.59 & $1.08-2.26^{*}$ \\
\hline Diseases of the kidney and the ureter & 26 & 1.79 & $1.17-2.63^{*}$ \\
\hline Diseases of the female genital organs and disorders of the breast & 0 & 0.00 & $0.00-20.50$ \\
\hline Other diseases of the genitourinary system & 5 & 1.05 & $0.33-2.48$ \\
\hline Congenital malformations, deformities and chromosomal abnormalities & 2 & 4.12 & $0.39-15.15$ \\
\hline Congenital malformations of the nervous system & 0 & 0.00 & $0.00-235.23$ \\
\hline Congenital malformations of the circulatory system & 0 & 0.00 & $0.00-19.26$ \\
\hline Other congenital malformations, deformities and chromosomal abnormalities & 2 & 7.54 & $0.71-27.73$ \\
\hline Symptoms, signs and abnormal findings not elsewhere classified & 20 & 1.13 & $0.69-1.74$ \\
\hline Cardiac arrest, death without assistance and other unknown cause of mortality & 9 & 1.13 & $0.51-2.15$ \\
\hline Senility & 7 & 1.25 & $0.50-2.59$ \\
\hline Rest of symptoms, signs and clinical abnormal findings & 4 & 0.96 & $0.25-2.49$ \\
\hline External causes of mortality & 27 & 1.36 & $0.90-1.98$ \\
\hline
\end{tabular}

$O$ observed deaths; SMR standardised mortality ratio; 95\% CI 95\% confidence interval of the SMR

*Statistically significant at $\alpha=0.05$

\section{Cancer causes}

The SMR for lung cancer was statistically significant (SMR =3.90) among patients diagnosed in 1985-1994 but not in those diagnosed later. Two cohort studies carried out in the mid- $80 \mathrm{~s}$ found higher risk of lung cancer after the BC diagnosis, suggesting an association between this cancer, as second tumour, and side effects of RT $[15,16]$. In the line of these studies, at the beginning of 1990s, the sites that typically received the highest radiation exposures ( $>1 \mathrm{~Gy}$ ) were oesophagus, lung, pleura, bone and soft tissues, which were irradiated with higher doses than those at the end of the 1990s [17, 18]. In our regions, changes in radiation exposures were introduced in the year 2000 [12], and this could be the reason for the decrease of the SMR in 1995-2004.
The proportion of women with locoregional $\mathrm{BC}$ who are treated with RT has increased over the years, and the techniques used in RT have improved substantially by decreasing the volumes of non-breast-irradiated tissues. Likewise, the post-surgery conservative RT of the breast after partial mastectomy would also decrease the doses compared to the post-mastectomy RT and this would entail a non-increased risk of lung cancer compared to the non-use of the RT [17, 18]. In a cohort recruited from 1973 to 2005 , there was a small but significant increase in the risk of lung cancer and other regions receiving high doses after conservative surgery [17]. We must take into account two factors: lung cancer mortality rates among women in Girona and Tarragona were very low in 1985-1994 [19] as well as smoking prevalence in the study cohort. On the other hand, death certificates 
(a) $\leq 59$
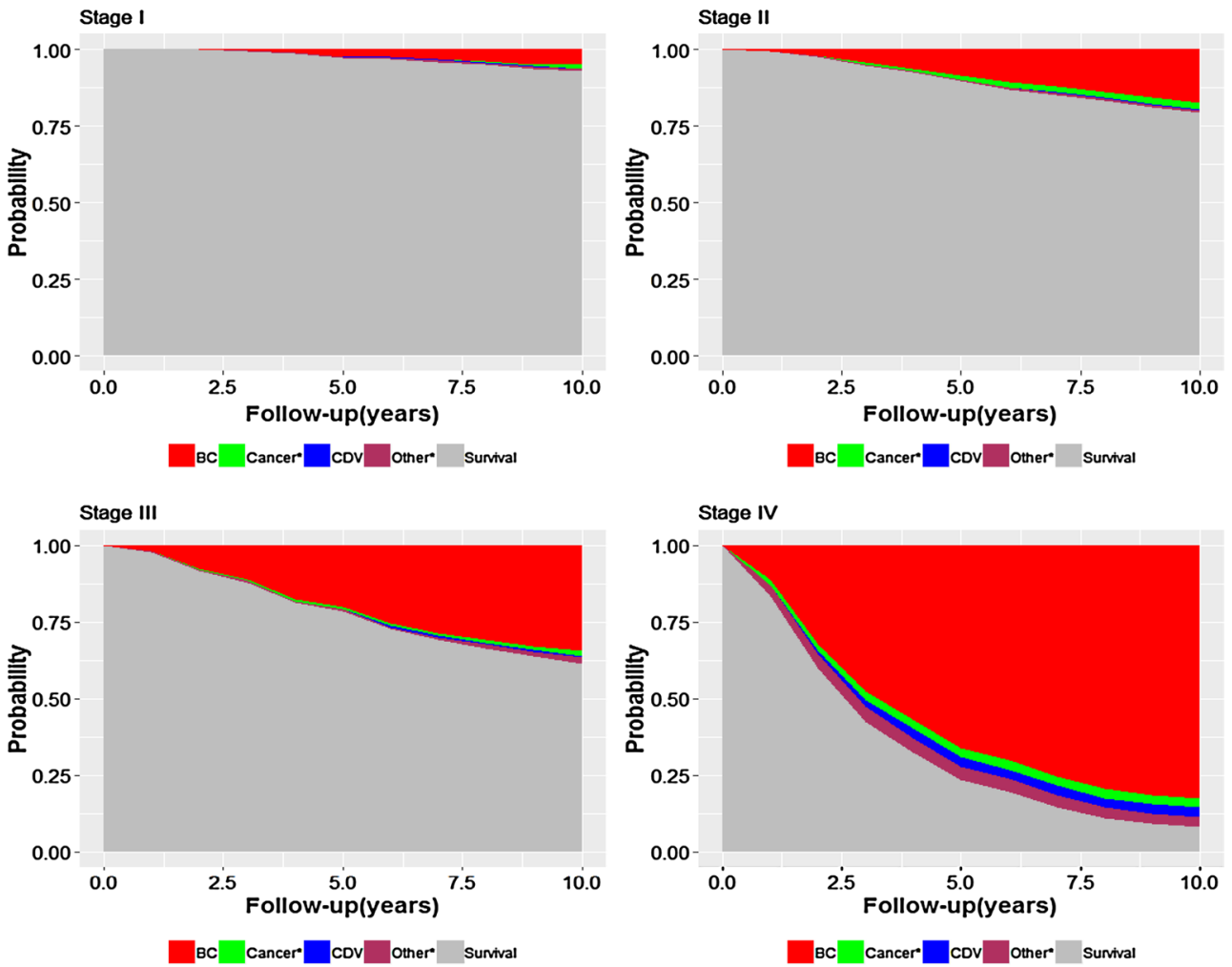

(b) [60-69]
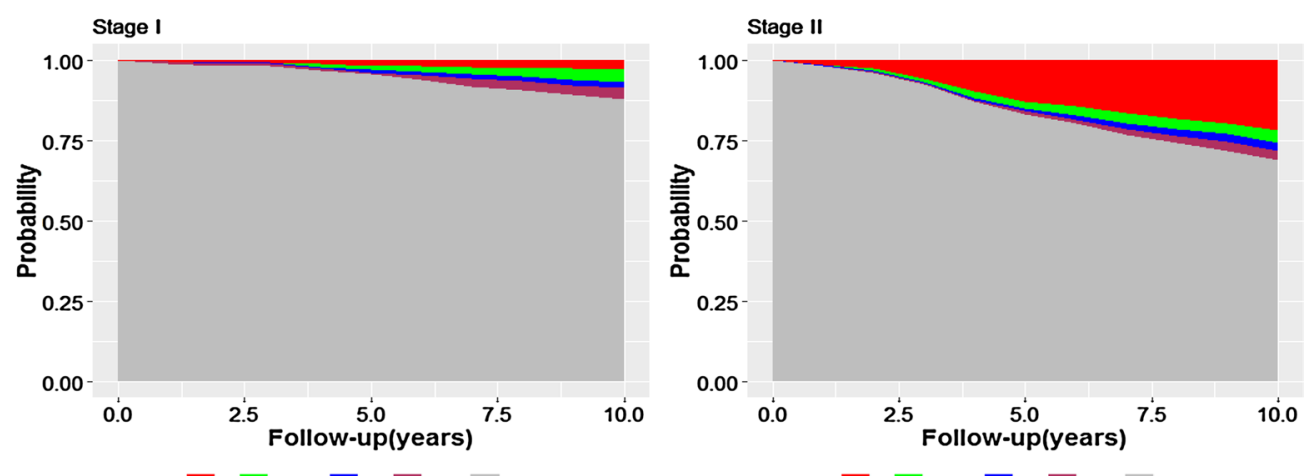

$\square$ BC $\square$ cancer- $\square$ cov $\square$ other $\quad$ Sunival
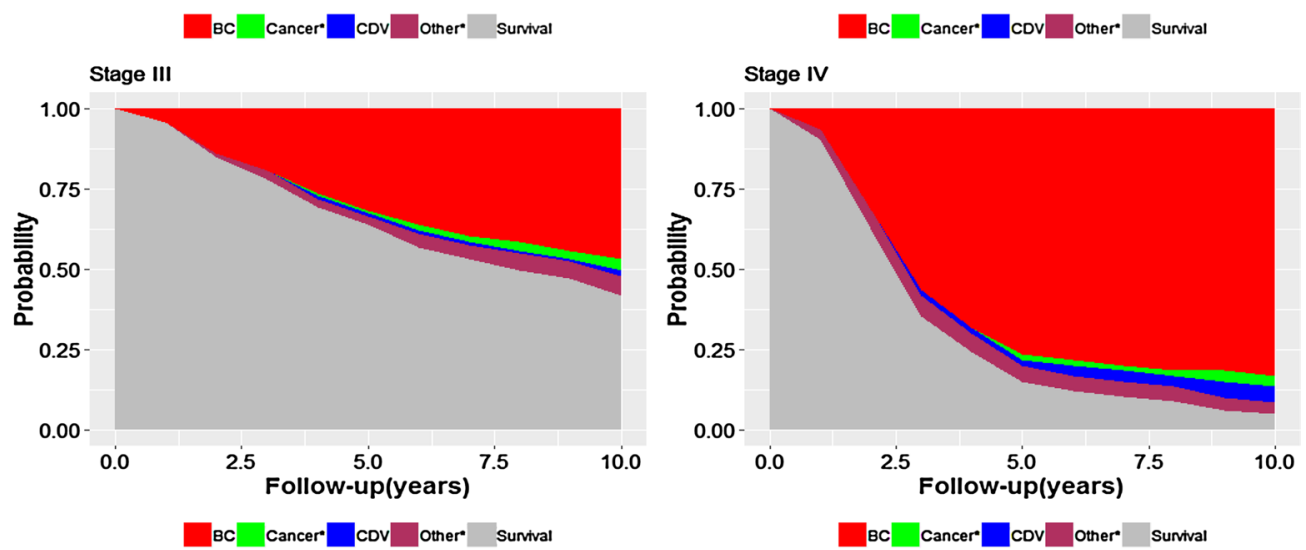

Fig. 1 Cumulative probability of cause-specific mortality and survival probability by age groups and across stages of $\mathrm{BC}$ at diagnosis during 1995-2004: a patients diagnosed of BC at ages $\leq 59$ years; $\mathbf{b}$ patients diagnosed of $\mathrm{BC}$ comprised from 60 to 69 years of age. $B C$ breast cancer; Cancer* cancers other than $\mathrm{BC}$; $C D V$ cardiovascular; Other* other causes of death 
(a) [70-74]
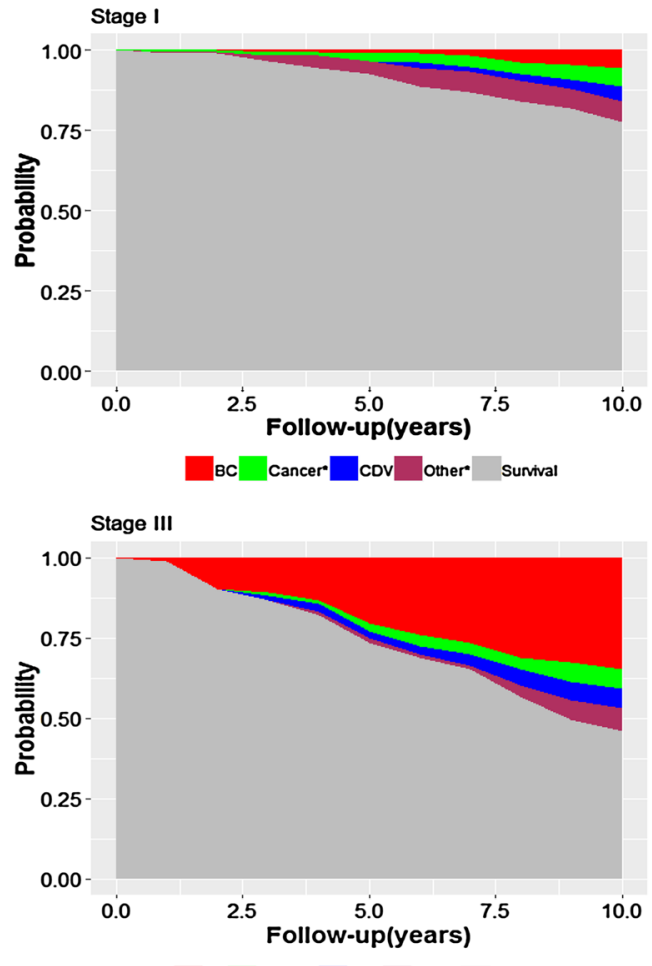

(b) $>74$
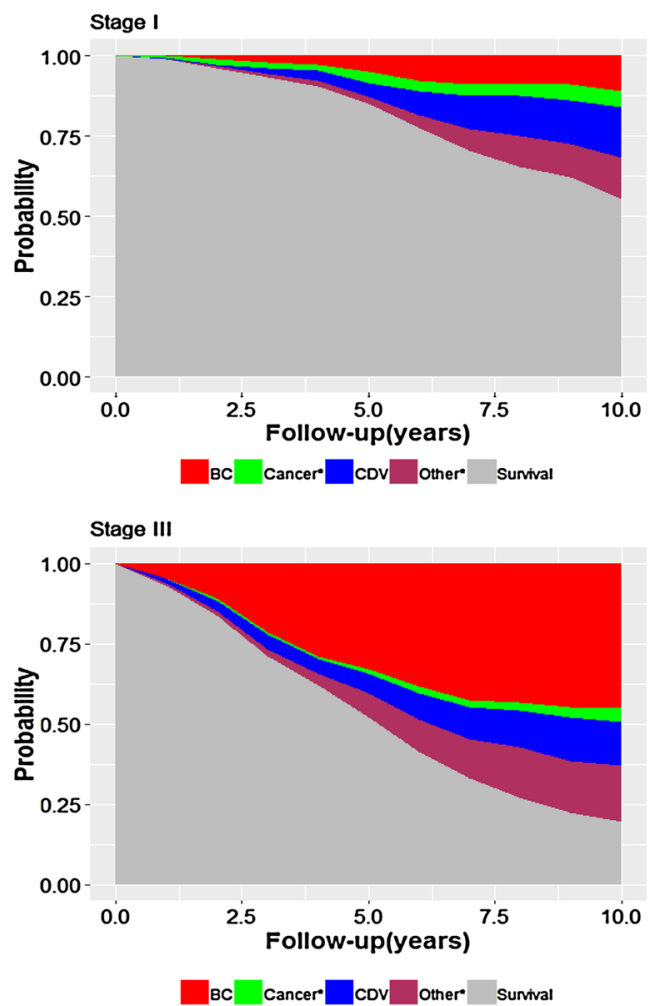

Stage II

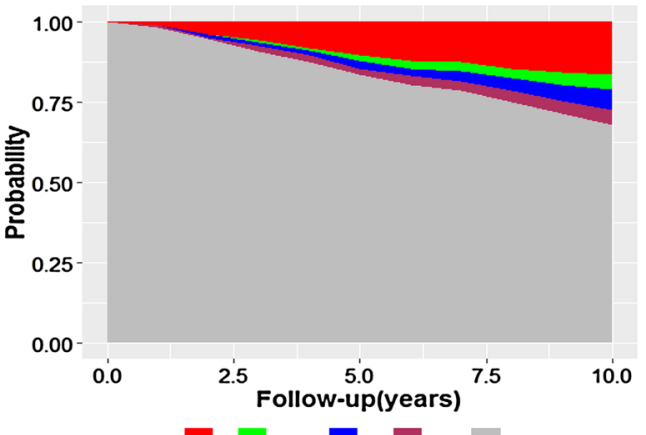

BC Cancer- $\square$ cov other- Sunvival

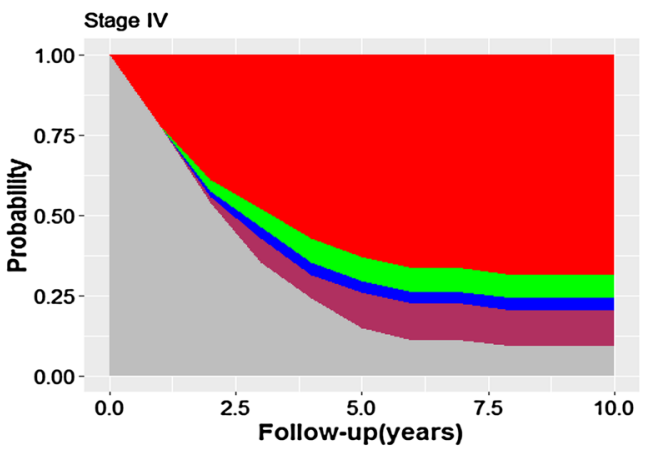

BC Cancer $\square$ cDv $\square$ other- Sunival
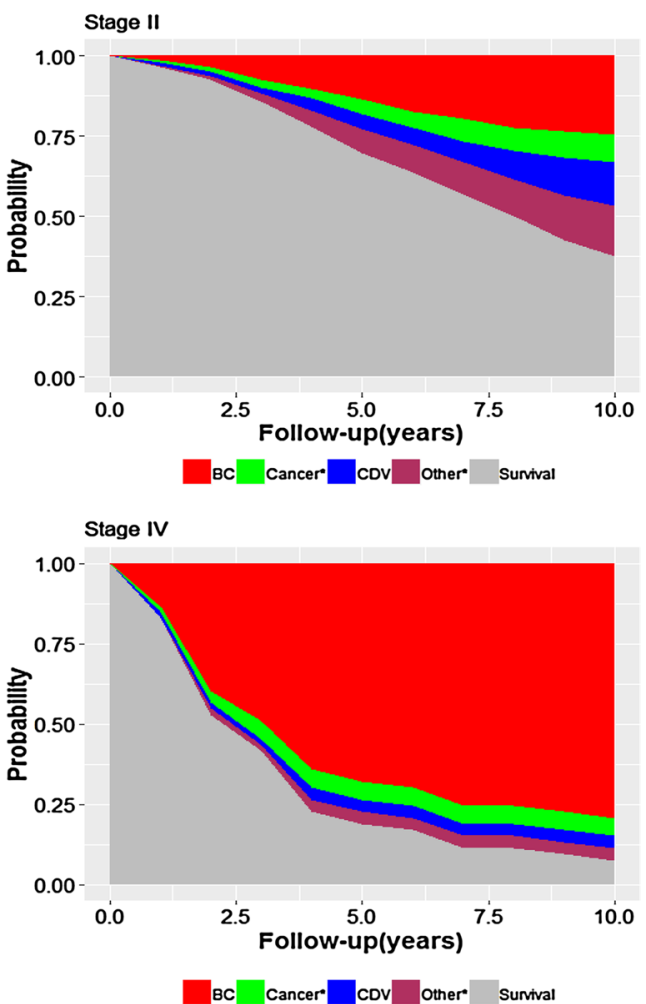

Fig. 2 Cumulative probability of cause-specific mortality and survival probability by age groups and across stages of $\mathrm{BC}$ at diagnosis during 1995-2004: a patients diagnosed of BC at ages (70-74) years and $\mathbf{b}$ patients diagnosed of $\mathrm{BC}$ beyond 74 years. $B C$ breast cancer; Cancer* cancers other than $\mathrm{BC}$; $C D V$ cardiovascular; Other* other causes of death 
might be coding some lung cancer metastases as primary lung cancer [19]. In absolute terms, lung cancer is the second most involved type of cancer after BC, so it is important to monitor this risk in patients treated with RT $[17,18]$.

Evidence suggests an increased risk of bone and soft tissue tumours after BC in population-based studies about second cancers, where sarcomas and angiosarcoma are the most frequent tumours associating its risk with RT [20]. In our study, the incidence of these tumours is very low $(n=3)$, but we found an SMR $=10.25$ of the malignant tumours of bone and articular cartilages among women diagnosed during 1985-2004. However, this could be an effect of tumour misclassification. We did not find an increased risk in bone tumours among women diagnosed during 1995-2004, either in soft tissue tumours-in either of the two periods-or in esophageal cancers. The results observed in our study suggest that the doses of RT applied in the BC were lower in the second period.

In the line of our study, several studies have noted an increased risk of developing uterine corpus tumours after a BC $[16,21]$. In some studies this risk has been linked with shared reproductive factors such as nulliparity or late age at diagnosis [16], therapies, such as tamoxifen in invasive BC [22], or shared risk factors [16, 21-23]. Certain studies have shown an increased risk of developing endometrial cancer after $\mathrm{BC}$ regardless of oestrogen receptor or progesterone status [23], raising a concern whether common etiological factors among BC subtypes might increase the susceptibility to develop endometrial cancer [23].

Risk of ovarian cancer mortality has also been reported in several studies of second tumours after the treatment of BC [16, 19, 21, 24]. Individuals with germline mutations in cancer susceptibility genes, such as BRCA1 and BRCA2, are at high risk of developing breast and ovarian cancer [21, 24], whereas increased mortality of ovarian cancer can be explained by shared inherited susceptibility genes such as BRCA1 or BRCA2, especially in young women [24].

Leukaemia mortality showed a significant 10 -year risk $\left(\mathrm{SMR}_{1985-2004}=2.05\right)$. Therapy-associated secondary leukaemias might occur between 0.3 and $0.5 \%$ after antineoplastic therapy of solid tumours such as cancers of the breast, lung, testicles and ovaries, and sarcomas [25]. Risk of other haematological malignant tumours was found in the 1985-1994 cohort. This risk could be explained by side effects of RT [25]. In our study, we did not find a significant SMR from other types of malignant tumours (head and neck, thyroid, melanoma or others).

Significant risk for colon cancer after 10 years of BC diagnosis was also detected $\left(\mathrm{SMR}_{1985-2004}=1.44\right)$. The studies about time interval of colorectal cancer risk since $\mathrm{BC}$ diagnosis show that most women develop their second malignancy between 1 and 10 years [26], therefore, evidence suggests that women diagnosed with $\mathrm{BC}$ before 50 years of age should start colorectal screening 5 years earlier than the general population [26].

\section{Non-cancer causes}

In our previous study [12], we suggested that CVD and OC mortality might increase with older age at diagnosis. In the present study, the competing risk analysis showed that the probability to die from non-cancer surpassed that of cancer (except BC) among patients diagnosed in stages II-III independent of the age at the diagnosis of $\mathrm{BC}$, whereas in stage $\mathrm{I}$, this pattern was observed in elderly patients.

In our study, we observed a significant SMR for diabetes mellitus. Pre-existing diabetes mellitus in women with BC has been associated with a $37 \%$ increased risk for all-cause mortality and with a $17 \%$ increased risk for BC mortality and mortality of women with BC is significantly increased for diabetic patients compared with non-diabetic patients [27]. The links between diabetes and BC are explained by common risk factors (overweight/obesity, dietary errors, physical inactivity), biological changes and the impact of some anti-diabetic treatments or hormonotherapy. These studies conclude that physicians facing a diabetic patient treated for $\mathrm{BC}$ have a role in choosing the best anti-diabetic treatment and implementing the lifestyle modifications [27].

The slight EM from diseases of the circulatory system is the one that produces a greater increase in deaths per 10,000 patient-years since deaths from this type of diseases represent the first cause of mortality in women in the populations of Girona and Tarragona. The ED corresponding to the group "Other heart diseases" might be due to poor certification and/or coding of the cause of death. It has been determined that cardiac mortality is positively correlated with the cardiac dose-volume [28]. RT regimens used in BC treatment during 1989-2005 increased the risk of cardiovascular disease, whereas anthracycline-based chemotherapy regimens increased the risk of congestive heart failure [29]. In our study, EM was only observed among women diagnosed in 1985-1994 and after 20 years of follow-up, possibly because the irradiation doses in 1995-2004 were lower than in 1995-2004.

We found a significant SMR for diseases of the nervous system except for meningitis and Alzheimer's disease for the 1985-1994 cohort. The real cause of death of these women is difficult to validate, but evidence suggests that chemotherapy and RT could lead to long-term side effects in brain [28].

Mortality by "Osteoporosis and pathological fracture" was only observed for the global period possibly because of the few number of deaths for this cause. On the other hand, certain percentage of these deaths has been probably caused by bone metastases and, therefore, primarily by BC. 
Finally, we found a significant SMR for diseases of kidney and ureter in the first decade that was not statistically significant in the second decade. It has been hypothesised that chronic kidney disease could be a risk factor for mortality in patients with $\mathrm{BC}$, but in a recent study, this disease does not appear to have a significant impact on outcomes in these patients [30]. In our study, we reviewed the clinical records of $50 \%$ of the death certificates as well as all registry records of diseases of kidney and ureter, and we found that a non-negligible proportion of cases suffered from chronic renal failure before the diagnosis of $\mathrm{BC}$.

\section{Strengths and limitations}

The main strengths of this study are: (a) it is populationbased, and this allows obtaining unbiased results, and (b) it has long follow-up. The main limitation lies in the potentially limited quality of the data since death certificates might present quality problems of various kinds [12, 19]. An effort was made for minimising that issue by determining the exact type of cancer among deceased patients with poorly defined tumours. We noted two other limitations: (a) the design of this study has not allowed to evaluate the risk of death by contralateral $\mathrm{BC}$ and (b) the treatment received by each patient could not be retrieved from registry records [12], therefore, it was not possible to study the association of the different types of treatment with the causes of mortality in the cohort.

\section{Conclusions}

In our study, at 10 and 20 years after the diagnosis of $\mathrm{BC}$, women who did not die from $\mathrm{BC}$ had a $20 \%$ excess risk of dying from other causes than BC. This excess risk of dying from these causes must be considered clinically for at least 20 years after the diagnosis of $\mathrm{BC}$.

Acknowledgements This work was supported by (1) Instituto de Salud Carlos III through the Project PI14/01041, co-funded by FEDER funds/European Regional Development Fund (ERDF)-a way to Build Europe-//FONDOS FEDER "una manera de hacer Europa" and by (2) Agència d'Avaluació d'Universitats i Recerca (2017SGR00735) from Generalitat de Catalunya. We also thank CERCA Programme/ Generalitat de Catalunya for institutional support.

\section{Compliance with ethical standards}

Conflict of interest The funders had no role in the design of the study, the collection, analysis, or interpretation of the data, the writing of the manuscript, or the decision to submit the manuscript for publication. The authors state that there are no conflicts of interest concerning this study.
Research involving human participants and/or animals This article does not contain any studies with human participants or animals performed by any of the authors.

Informed consent Informed consent was obtained from all individual participants included in the study.

OpenAccess This article is distributed under the terms of the Creative Commons Attribution 4.0 International License (http://creativeco mmons.org/licenses/by/4.0/), which permits unrestricted use, distribution, and reproduction in any medium, provided you give appropriate credit to the original author(s) and the source, provide a link to the Creative Commons license, and indicate if changes were made.

\section{References}

1. Bray F, Ferlay J, Soerjomataram I, Siegel RL, Torre LA, Jemal A. Global cancer statistics 2018: GLOBOCAN estimates of incidence and mortality worldwide for 36 cancers in 185 countries. CA Cancer J Clin. 2018;68(6):394-424.

2. Galceran J, Ameijide A, Carulla M, Mateos A, Quiros JR, Rojas D, et al. Cancer incidence in Spain, 2015. Clin Transl Oncol. 2017;19(7):799-825.

3. Chirlaque MD, Salmerón D, Galceran J, Ameijide A, Mateos A, Torrella A, et al. Cancer survival in adult patients in Spain. Results from nine population-based cancer registries. Clin Transl Oncol. 2018;20(2):201-11.

4. Crocetti E, Roche L, Buzzoni C, di Costanzo F, Molinié F, Caldarella A, et al. Trends in net survival from breast cancer in six European Latin countries: results from the SUDCAN populationbased study. Eur J Cancer Prev. 2017;26:S85-91.

5. Overgaard M, Jensen M. Postoperative radiotherapy in high-risk postmenopausal breast cancer patients given adjuvant tamoxifen: Danish Breast Cooperative Group DBCG 82c randomized trial. Lancet. 1999;353:1641-848.

6. Early Breast Cancer Trialists' Collaborative Group. Effects of chemotherapy and hormonal therapy for early breast cancer on recurrence and 15-year survival: an overview of the randomized trials. Lancet. 2005;365(9472):1687-717.

7. Allemani C, Minicozzi P, Berrino F, Bastiaannet E, Gavin A, Galceran J, et al. Predictions of survival up to 10 years after diagnosis for European women with breast cancer in 2000-2002. Int J Cancer. 2013;132(10):2404-12.

8. Early Breast Cancer Trialists' Collaborative Group. Favourable and unfavourable effects on long-term survival of radiotherapy for early breast cancer: an overview of the randomized trials. Lancet. 2000;355:1757-70.

9. Roychoudhuri R, Robinson D, Putcha V, Cuzick J, Darby S, Møller H. Increased cardiovascular mortality more than fifteen years after radiotherapy for breast cancer: a population-based study. BMC Cancer. 2007;15(7):9.

10. Bradshaw PT, Stevens J, Khankari N, Teitelbaum SL, Neugut AI, Gammon MD. Cardiovascular disease mortality among breast cancer survivors. Epidemiology. 2016;27(1):6-13.

11. Hooning MJ, Aleman BMP, van Rosmalen AJM, Kuenen MA, Klijn JGM, van Leeuwen FE. Cause-specific mortality in longterm survivors of breast cancer: a 25-year follow-up study. Int J Radiat Oncol Biol Phys. 2006;64(4):1081-91.

12. Clèries R, Ameijide A, Buxó M, Martínez JM, Marcos-Gragera R, Vilardell ML, et al. Long-term crude probabilities of death among breast cancer patients by age and stage: a population-based survival study in Northeastern Spain (Girona-Tarragona 1985-2004). Clin Transl Oncol. 2018;20(10):1252-60. 
13. Breslow NE, Day NE. Statistical methods in cancer research. Volume II-the design and analysis of cohort studies. IARC Sci Publ. 1987;82:1-406.

14. Colzani E, Liljegren A, Johansson AL, Adolfsson J, Hellborg H, Hall PF, et al. Prognosis of patients with breast cancer: causes of death and effects of time since diagnosis, age, and tumour characteristics. J Clin Oncol. 2011;29(30):4014-21.

15. Taylor CW, Povall JM, McGale P, Nisbet A, Dodwell D, Smith JT, et al. Cardiac dose from tangential breast cancer radiotherapy in the year 2006. Int J Radiat Oncol Biol Phys. 2008;72(2):501-7.

16. Harvey EB, Brinton LA. Second cancer following cancer of the breast in Connecticut, 1935-82. Natl Cancer Inst Monogr. 1985;68:99-112.

17. de Gonzalez AB, Curtis RE, Gilbert E, Berg CD, Smith SA, Stovall M, et al. Second solid cancers after radiotherapy for breast cancer in SEER cancer registries. Br J Cancer. 2010;102:220-6.

18. Clarke M, Collins R, Darby S, Davies C, Elphinstone P, Evans $\mathrm{E}$, et al. Effects of radiotherapy and of differences in the extent of surgery for early breast cancer on local recurrence and 15-year survival: an overview of the randomised trials. Lancet. 2005;366:2087-106.

19. Borràs JM, Piñol JL, Izquierdo A, Borràs J. Analysis of cancer incidence, survival and mortality according to the main tumoural localizations, 1985-2019: lung cancer. Med Clin (Barc). 2008;131(Suppl 1):53-7.

20. Huang J, Mackillop WJ. Increased risk of soft tissue sarcoma after radiotherapy in women with breast carcinoma. Cancer. 2001;92(1):172-80.

21. Mellemkjaer L, Friis S, Olsen JH, Scélo G, Hemminki K, Tracey $\mathrm{E}$, et al. Risk of second cancer among women with breast cancer. Int J Cancer. 2006;118(9):2285-92.

22. Fisher B, Costantino JP, Redmond CK, Fisher ER, Wickerham DL, Cronin WM, et al. Endometrial cancer in tamoxifen-treated breast cancer patients: findings from the National Surgical Adjuvant Breast and Bowel Project (NSABP) B-14. J Nat Cancer Inst. 1994;86(7):527-37.

23. Liu J, Jiang W, Mao K, An Y, Su F, Kim BYS, et al. Elevated risks of subsequent endometrial cancer development among breast cancer survivors with different hormone receptor status: a SEER analysis. Breast Cancer Res Treat. 2015;159(2):439-45.

24. Molina-Montes E, Pollán M, Payer T, Molina E, Dávila-Arias C, Sánchez MJ. Risk of second primary cancer among women with breast cancer: a population-based study in Granada (Spain). Gynecol Oncol. 2013;130(2):340-5. https://doi.org/10.1016/j. ygyno.2013.04.057.

25. Haase D, Hanf V, Schulz T. Therapy-related hematologic neoplasias after breast cancer Epidemiologic, etiologic and cytogenetic aspects and new risk factors according to published data and own results. Med Klin (Munich). 2004;99(9):506-17.

26. Lai JH, Park G, Gerson LB. Association between BC and the risk of colorectal cancer. Gastrointest Endosc. 2017;86:429-41.

27. García-Esquinas E, Guinó E, Castaño-Vinyals G, Pérez-Gómez B, Llorca J, Altzibar JM, et al. Association of diabetes and diabetes treatment with incidence of breast cancer. Acta Diabetol. 2016;53(1):99-107. https://doi.org/10.1007/s00592-015-0756-6.

28. Early Breast Cancer Trialists' Collaborative Group, McGale P, Taylor C, Correa C, Cutter D, Duane F, et al. Effect of radiotherapy after mastectomy and axillary surgery on 10-year recurrence and 20-year breast cancer mortality: meta-analysis of individual patient data for 8135 women in 22 randomised trials. Lancet. 2014;383(9935):2127-35.

29. Boekel NB, Schaapveld M, Gietema JA, Russell NS, Poortmans $\mathrm{P}$, Theuws JC, et al. Cardiovascular disease risk in a large, population-based cohort of breast cancer survivors. Int J Radiat Biol Phys. 2016;94(5):1061-72.

30. Dubose AC, Chu QD, Li BD, Kin RH. Is chronic kidney disease an independent risk factor for mortality in breast cancer? J Surg Res. 2013;184(1):260-4.

Publisher's Note Springer Nature remains neutral with regard to jurisdictional claims in published maps and institutional affiliations. 